\title{
Intervención social y el debate sobre lo público
}

\author{
GRUPO DE INVESTIGACIÓN EN INTERVENCIÓN Y \\ RESPONSABILIDAD SOCIAL (2014). Intervención socialy el debate \\ sobre lo público: reflexiones conceptuales y casos locales. Colección \\ "El Sur es Cielo Roto", No. 9. Cali, Colombia. Universidad Icesi, \\ Facultad de Derecho y Ciencias Sociales. 258 pp.
}

Este libro es resultado del trabajo de reflexión llevado a cabo desde el 2006 por el Grupo de investigación en Intervención y Responsabilidad Social de la Universidad Icesi. El libro, una compilación de escritos conceptuales y empíricos, presenta los resultados de investigaciones sobre la construcción de lo social en Cali. ${ }^{1}$ Con el fin de abordar la complejidad de lo que significa transformar lo social, el grupo se enfoca en la construcción de lo público como punto de encuentro de múltiples actores y miradas.

Los autores abordan la transformación de lo social, a través de la construcción de lo público descomponiéndolo en los roles asumidos por actores con diversas perspectivas, facilitando así su operacionalización. El postulado es que lo público se construye desde el estado, las ONG y las empresas, principalmente a través de sus fundaciones empresariales. En este caleidoscopio, los autores buscan articularse alrededor de dos preguntas: ¿Cómo se construye lo público en un contexto en el cual los roles tradicionales

\footnotetext{
1. Un anterior trabajo investigativo del Grupo de investigación en Intervención y Responsabilidad Social de la Universidad Icesi sobre las distintas formas que ha tomado la intervención social en la ciudad de Cali puede encontrase en PAZ RUEDA, Ana Lucia et al. (2010). ¿Cómo se transforma lo social? Discursosy prácticas de intervención en Cali. Cali, Colombia: Universidad Icesi, Facultad de Derecho y Ciencias Sociales.
} 
de los actores han cambiado? ¿Cuáles son las tensiones inherentes a la construcción de lo público y como pueden resolverse?

Estas son preguntas significativas, pero difíciles de abordar dada la naturaleza amorfa de lo público y las fronteras cada día más tenues entre las esferas de lo público y lo privado. Por ejemplo, las empresas han entrado a asumir cada vez más roles políticos, como la provisión de bienes públicos o la regulación de lo que significa el comportamiento responsable (Crane, Matten, y Moon, 2008), lo cual puede generar una desreponsabilización del estado. Este libro es entonces el reflejo del carácter multidisciplinar que acompaña, y debe acompañar, lo público, su concepción y construcción. En él se materializan miradas de sociólogos, antropólogos, economistas, trabajadores y psicólogos, generando una riqueza conceptual, una de las fortalezas del libro.

Los 10 capítulos del libro están organizados en dos partes. Una primera apuesta conceptual (textos 1 al 6) y una segunda parte empírica, que se centra en el estado y el tercer sector (textos 7 al 10).

En la introducción, se abordan cuatro grandes tensiones que se derivan de la construcción de lo público: el trabajo con sujetos excluidos y no-ciudadanos, con sujetos no autónomos, en medio de relaciones de poder y subordinación y en las cuales no se reconoce al otro como individuo. Estas tensiones se materializan en todo tipo de intervención, pero se exacerban en el marco de las intervenciones llevadas a cabo por las empresas, expone la autora.

En los aportes conceptuales se plasman los diferentes roles que cada uno de los actores- Estado, ONG y empresas- han tenido en la construcción de lo público. Así, el primer aporte conceptual (texto 1) tiene por objetivo dar una mirada a los roles de estos tres actores ONG planteándose la inquietud del origen de la construcción de lo público en un mundo en donde las esferas están más que nunca entrelazadas. Sin enfocarse de forma profunda en cada uno de los actores, Miriam Fajardo, nos presenta una conceptualización muy interesante de los roles políticos que han tomado las ONG. Pasando de suplir los roles estatales a fomentar la participación política de poblaciones vulnerables a cumplir una función internacionalizadora en la apropiación pionera de temas no abordados por los otros dos actores.

Los textos 2, 3 y 4 conceptualizan la intervención social desde la perspectiva histórica (texto 2), desde la complejidad de los problemas sociales que abordan los actores (texto 3 ) o delimitándola como objeto de estudio (texto 4). Viviam Unás y Paola Ocampo (texto 2) se centran en la idea de la intervención social, que se nutre de sus prácticas antecesoras como la filantropía o la intelectualidad orgánica. En el texto 3, James Cuenca, José Eduardo Sánchez y Mary Hellen Burbano Cerón, postulan que la intervención social como campo de acción puede ser entendida como una repuesta a una crisis de integración de diversos grupos a la sociedad, a las deficiencias del sistema capitalista o a la inadaptación de los métodos de gestión social actuales. En el texto 4, Ana Lucía 
Paz contribuye conceptualmente a la construcción de una sociología de la intervención, mostrando los cambios en los problemas que se abordan, los beneficiarios y las formas de intervención.

Así, los tres textos parecen entrelazados por la idea de que los problemas sociales, fragmentados, múltiples y complejos, necesitan una mirada articulada de los tres actores. Además hay una confluencia en la idea de que la intervención social contemporánea se construye como una respuesta a la prevalencia del mercado y el retroceso del estado de bienestar, ya que "los cambios en la naturaleza de la intervención social en el país pasan por los cambios en el orden político, económico, social y jurídico" (pág. 76).

En los textos 5 y 6 la mirada se torna hacia la empresa privada. Edgar Orlando Benítez y Diego Fernando Varón, conceptualizan a la empresa privada de tres formas diferentes (texto 5): la empresa como negocio, la empresa como organización y la empresa como institución. En esta última la empresa puede considerarse un actor político en la medida en que "crea y recrea reglas sociales" (pág. 139), influyendo en el comportamiento individual. El texto 6 propone une reflexión crítica a la responsabilidad social empresarial ya que puede ser entendida como un mecanismo de control y poder.

En la segunda parte, el artículo 7 de Nathalia Muñoz Ballesteros abre la parte empírica con un análisis de las intervenciones del tercer sector en Cali entre el 2005 y el 2010. Mientras que los textos (8 y 9) exploran el proceso del Centro de Escucha de Potrero Grande. Esta parte cierra con un artículo centrado en el actor estado analizando el cambio en la representación y abordaje de los problemas sociales.

En esta gran variedad de textos, en algunos momentos podría habérsele dado más peso a los argumentos y un mayor sustento empírico. Además, en varias ocasiones, el hilo conductor de los diferentes textos se desdibuja: se conceptualizan los roles políticos que asumen los diferentes actores sin ahondar en las tensiones que se crean. O por el contrario en otros textos se abordan las tensiones sin combinarlas a los roles políticos. En el ámbito de la empresa privada sorprende que no se aborde el papel que han jugado y juegan las fundaciones empresariales en la construcción de lo público (Rojas y Morales, 2006).

A pesar de que no se mencionan explícitamente, el libro abre la puerta a diversas pistas de investigación. Un eje de investigación futuro podría ser la indagación de las construcciones colectivas cuando los tres tipos de actores confluyen. En otras palabras, sería interesante en la continuidad de los trabajos entender de qué forma los diferentes actores estado-ONG-empresa se relacionan para construir lo social. ¿Cuáles son las implicaciones cuando todas las esferas construyen lo público? ¿Qué dinámicas de confrontación-colaboración surgen? Experiencias han mostrado las dificultades que esta articulación supone por lo cual una nueva tensión podría ponerse de manifiesto o dar respuestas a las tensiones previamente enunciadas. 
Sin embargo, las fortalezas de este trabajo son variadas. Primero, el abordaje de lo público desde la multiplicidad. Los diferentes textos evocan ONG, estado y empresas privadas. Segundo, los ejemplos empíricos de intervención movilizados, particularmente, el del centro de escucha de potrero grande que pueden ser explotados para múltiples fines prácticos y académicos. Finalmente, en general, el libro constituye un buen panorama para iniciarse en las problemáticas asociadas a la construcción de lo público en Cali, tanto para el mundo de la academia como el de la praxis. Una invitación a reflexionar sobre lo público como una construcción colectiva, en la cual los roles asumidos por cada uno de los actores abordados lejos de delimitarse en la acción, se entrelazan en la búsqueda de mejores condiciones sociales locales.

\section{Referencias}

CRANE, A., MATTEN, D., \& MOON, J. (2008). Corporations and citizenship. Cambridge: Cambridge University Press.

ROJAS, C., \& MORALES, G. (2006). Private contributions to the public sphere. In C. Sanborn y F. Portocarrero (Eds.), Philanthropy and social change in Latin America. Cambridge, MA: Harvard University Press. 